\title{
Does Workplace Fun Buffer the Impact of Emotional Exhaustion on Job Dissatisfaction?: A Study of Health Care Workers
}

\author{
Katherine A. Karl \\ Marshall University \\ Joy V. Peluchette \\ University of Southern Indiana
}

\begin{abstract}
This study examined health care workers' $(\mathrm{N}=142)$ attitudes toward workplace fun and the level of fun they experienced at work as well as their emotional labor, emotional exhaustion and job satisfaction. Our results showed that the negative impact of emotional exhaustion on job satisfaction was significantly lower for health care workers' who experienced greater levels of fun at work. In general, the health care workers in this sample expressed positive attitudes toward workplace fun. These results, their implications, and directions for future research are discussed.
\end{abstract}

\section{Introduction}

Should the workplace be fun? A growing number of business writers and consultants would agree, arguing that fun is essential for enhancing employee motivation and productivity, reducing stress, and increasing customer satisfaction (Lundin, Paul, \& Christensen, 2002; McGhee, 2000; Paulson, 2001; Ramsey, 2001, Weiss, 2002). In support, recent analyses of Fortune's "100 Best Companies to Work For" show that a 'fun work environment' is one of the factors distinguishing superior performers from others (Chan, Gee \& Steiner, 2000; Joyce, 2003). But, can this same philosophy be extended to health care... a workplace that typically deals with the more serious and/or tragic aspects of life? It appears so.

Since the release of the best-selling Fish! books (Lundin, Paul, \& Christensen, 2002, 2003; Lundin, Christensen, Paul, \& Strand, 2002), many health care organizations have been touting widespread success with the introduction of a fun philosophy into their workplace including Silver Cross Hospital (Joliet, IL), Cooley Dickinson (Northhampton, CT), and Knoxville Area Community Hospital (Mellen, 2003; "FISH! Philosophy," 2003; "Employees 'KACH-the-Attitude"', 2004). CEO Rob Curry of Banner Thunderbird Medical Center believes that his hospital's consistently high patient satisfaction scores can be traced to its lighthearted approach to health care, arguing that "when your employees are happy, then your patients, by and large, will be happy too" ("Patient Care Performed With Flair," 2004).

As illustrated in the following model, the purpose of this paper is to examine whether the negative impact of emotional exhaustion on job satisfaction is significantly lower for health care workers' who experience greater levels of fun at work than it is for those experiencing lower levels of fun. In addition, the model shows that emotional labor influences emotional exhaustion which, in turn, influences job (dis)satisfaction. The model also shows that attitudes toward workplace fun will influence the level of fun 
experienced at work. While there are undoubtedly many individual (e.g., age, gender, personality, experience, occupation) and organizational (e.g., culture, trust, industry) antecedents that may influence attitudes towards fun, these factors are beyond the scope of the present research.

\section{Figure 1. Theoretical Model}

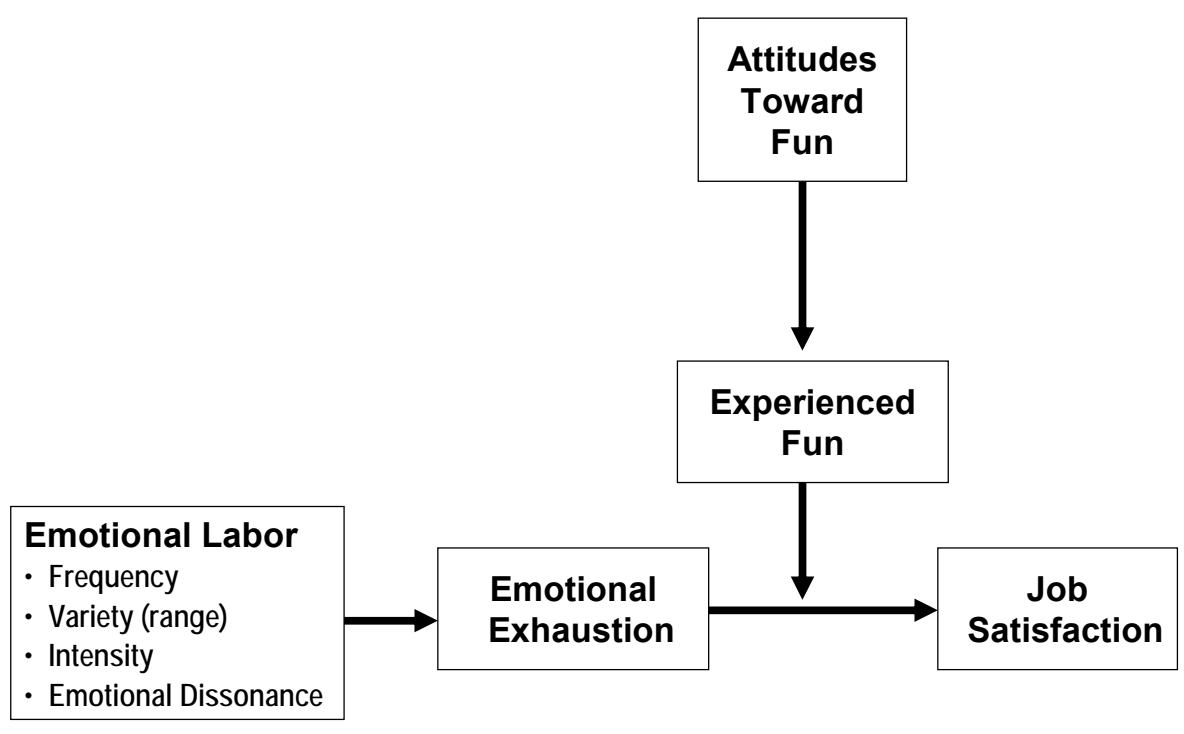

\section{Emotional Labor}

All human service workers are vulnerable to a phenomenon known as emotional labor. This is a process of emotion management whereby individuals control their true emotions by displaying what they perceive as "acceptable" workplace behaviors and emotions (Ashforth \& Humphrey, 1993; Hochschild, 1983). Displaying such organizationally or professionally sanctioned emotions to customers, clients, or patients has been argued to be a form of labor since such effort involves planning and adjustment to situations that may require one to display emotions that one does not privately feel. While emotional labor has been examined in a variety of human service occupations (Ashforth \& Humphrey, 1993; Morris \& Feldman, 1997), it is particularly relevant in the health care industry (Gorman, 2000; Henderson, 2001; Scott, 2000). For example, James (1989) argued that emotional labor in health care "is hard work and can be sorrowful and difficult. It demands that the laborer gives personal attention, not just a formulaic response." A recent article published in the Journal of the American Medical Association (Larson \& Yao, 2005) went even further arguing that emotional labor should characterize all health care professions. They added that "physicians are more effective healers--and enjoy more professional satisfaction--when they engage in the process of empathy. We urge physicians first to recognize that their work has an element of emotional labor and, second, to consciously practice deep and surface acting to empathize with their patients." This suggests the need for a closer look at the role emotional labor plays in this professional work. 


\section{Emotional Exhaustion}

Emotional exhaustion is widely regarded as the core component of job burnout (Jackson, Schwab, \& Schuler, 1986; Maslach, 1982). It is characterized by feelings of tiredness and fatigue, a lack of energy, and the depletion of an individual's emotional resources (Moore, 2000). This has been found to be a common phenomenon in helping and caring professions and in customer-service positions. Early research suggested that nurses and social workers are likely to suffer from emotional exhaustion because their jobs often require the display of intense emotions (Kahn, 1983). Recent studies of various health care professions indicate that emotional exhaustion and job burnout are common problems associated with such occupations and that emotional detachment, increasing caseloads of patients, close interaction with patients, and emotional strain are prominent sources of emotional exhaustion (Dorz, Novara, Sica, \& Sanavio, 2003). The intensity of emotional exhaustion tends to be highest in acute care situations (Happell, Martin \& Pinikahana, 2003; Waldrop, 2003). Given the results of past research demonstrating a positive relationship between emotional labor and emotional exhaustion (Brotheridge \& Lee, 2003; Morris \& Feldman, 1997), we predict:

Hypothesis 1: The greater the degree of experienced emotional labor, the greater the emotional exhaustion.

Job Satisfaction

Job satisfaction has been found to be adversely affected by job-related stress and burnout (Cameron, Horsburgh \& Armstrong-Stassen, 1994; Lee \& Ashforth, 1996). For example, in a study of nurses, Aiken, Clarke, Sloane, Sochalski, and Siber (2002) found that workload was negatively related to burnout, emotional exhaustion, and job satisfaction. These authors reported that each additional patient per nurse was associated with a $23 \%$ increase in the odds of burnout and a $15 \%$ increase in the odds of job dissatisfaction.

While early theoretical work on emotional labor predicted a negative relationship between emotional labor and job satisfaction (Hochschild, 1983), more recent research found that high emotional labor was positively related to job satisfaction (Wharton, 1993). Rather than having a direct effect, it is more likely that emotional labor influences job satisfaction through its impact on emotional exhaustion. More specifically, we believe that emotional labor will not explain any additional variance in job satisfaction after controlling for emotional exhaustion. Therefore, we predict:

Hypothesis 2: Emotional exhaustion will mediate the relationship between emotional labor and job satisfaction.

\section{Experienced Fun}

Experienced fun is the extent to which a person perceives the existence of fun in their workplace. Proponents of fun at work claim that when people have fun doing their jobs, 
they are more energized and motivated, get along together better, provide better customer service, experience less stress, and are less like to be absent or leave the organization (Berg, 2001; Mariotti, 1999; Meyer, 1999). While many of these claims are based on anecdotal evidence, there is some empirical research, which suggests that humor plays an important role in buffering the potentially negative impact of job-related stress and emotional labor. For example, in his review of the literature, Martin (1996) found support for the notion that a healthy and playful sense of humor serves as a moderator for the aversive effects of stress on health and well-being. Broussine, Davies, and Scott (1999) conducted interviews with social service workers and found evidence that humor is used as a means of coping with distressing and threatening events. They reported that some social work is so distressing that "if it were not possible to laugh about it, it would be difficult to deal with" and that humor's effectiveness may stem from its ability to help individuals' create psychological distance from the stress they are experiencing (Broussine et al., 1999).

With regard to health care, humor appears to be receiving increasing attention as an appropriate means of stress release and building camaraderie. Leslie Gibson, a registered nurse and founder of The Comedy Connection at Morton Plant Hospital in Clearwater, FL, cites the advantages of using appropriate humor in the workplace and recommends ways to add humor to the break room, meetings, memos and newsletters, and in the patient lounge (Gibson, 2004). Empirical studies are finding that employees are also touting the benefits of workplace humor. For example, a recent study of both doctors and nurses of HIVIAIDS and oncology patients found that humor was indicated as an effective coping strategy in handling the emotional stress of their work (Dorz, et al, 2003). Similarly, a study of nurses found that an overwhelming majority (92\%) believed that laughing and a sense of humor helped them cope with workplace stress (Wooten, 1993). Almost half of the respondents reported that their immediate supervisor used and encouraged humor on the job, and about thirty percent indicated that there was some form of an active humor program evident at their worksite. Based on these findings, we propose that the level of fun experienced at work will moderate the relationship between emotional exhaustion and job satisfaction. More specifically:

Hypothesis 3: The negative impact of emotional exhaustion on job satisfaction will be significantly weaker for those individuals who experience greater levels of fun at work than it is for individuals who experience low levels of fun at work.

\section{Attitudes Toward Fun}

Just as with other psychological variables, individuals are likely to differ in their attitudes toward fun. As suggested by Aldag and Sherony (2001), these attitudes may have several dimensions. For example, there are likely to be differences in whether individuals view efforts to foster fun in the workplace as appropriate. This was the case at Cooley Dickinson Hospital where some employees reacted to the introduction of such activities as being "too silly for a hospital" (Mellen, 2003). Whether one finds fun at work as appropriate or not may depend on one's early socialization experiences, work history, peer influences, and personality characteristics (Aldag \& Sherony, 2001). These factors may also account for varying attitudes on the salience or importance of 
having fun at work. For some with high social needs, fun may play an important role in their job satisfaction. For others, this may be less important. In addition, the consequences of having fun at work are likely to be perceived differently by individuals. Some may view fun activities as a means of enhancing productivity, while others may see such efforts as creating chaos or more work for employees. One nurse's initial reaction to the introduction of the "Fish! Philosophy" at Missouri Baptist Medical Center was that this was "another program to drain more effort out of the staff" (Lundin, Christensen, Paul \& Strand, 2002). Clearly, evidence suggests that differences in attitudes toward fun warrant further investigation. To that end, this study will examine the relationship between attitudes toward fun and experienced fun. It is predicted that:

Hypothesis 4: Respondents with more positive attitudes toward fun will be more likely to report that they have experienced fun in the workplace.

\section{Method}

\section{$\underline{\text { Sample }}$}

The sample consisted of 142 health care workers enrolled in undergraduate and graduate health care administration courses at two medium-sized universities, one located in the Midwest and the other located in the southeastern part of the United States. Most of the respondents $(72 \%)$ were female and $54 \%$ were married. Although respondents ranged in age from 20 to 59 , the mean age was 30 years. About $40 \%$ of the sample consisted of registered nurses, with the remaining portion holding various clinical or administrative positions. The mean number of years in the current position was 3 years, with 7 years $(S D=7.07)$ in the profession. On average, respondents spent $80 \%$ of their work day interacting with others, with two-thirds of that time spent interacting with patients.

The surveys were distributed to the respondents during class by their instructor. Of the 200 surveys that were distributed, 187 were returned, producing a response rate of 93 percent. Because one of the surveys contained missing data and 44 of the respondents were not working in health care positions, 142 surveys were used in the data analysis.

\section{Survey Instrument}

The survey instrument consisted of two sections: (1) work-related emotions, and (2) work-related beliefs and attitudes. Demographic information was tapped through single item questions, including gender, age, marital status, education, job title, job tenure, and type of employer.

\section{Work-related emotions}

The work-related emotions section included measures of emotional labor and emotional exhaustion. Consistent with past research on the emotional labor concept (Brotheridge \& Lee, 2003; Morris \& Feldman, 1997), the emotional labor measure included items to assess the frequency, variety, and intensity of emotional requirements, as well as 
emotional dissonance (i.e., the conflict between genuinely felt emotions and organizationally or professionally sanctioned emotions).

The Emotion Work Requirements Scale (EWRS) by Best, Downey and Jones (1997), and two additional items developed for this study, were used to measure frequency, variety, and intensity. Sample items include: "I frequently reassure people who are distressed or upset", "I usually have to express friendly emotions (e.g., smiling, giving compliments, making small talk)", "I frequently have to hide my anger or disapproval about something someone has said or done" and, "I often hide my disgust over something someone has said or done." Two new items developed for this study reflect the often difficult and frustrating experience that health care workers face when they have to deliver bad news: "I usually have to tell people things they don't want to hear" and "I ordinarily have to attempt to get people to do things they don't want to do." For each item, respondents were asked to indicate their level of agreement using a 5-point scale (1=Strongly Disagree, 5=Strongly Agree).

Emotional dissonance was measured using three items adapted from Kruml and Geddes (2000). These authors reported a coefficient alpha of .80 for this three-item scale. Sample items include: "I show feelings to patients that are different from what I feel inside," and "I have to cover up my true feelings when dealing with patients." In addition, two additional items were added that assess the frequency of emotional dissonance experienced by respondents: "I spend most of my work day hiding my true emotions" and "I spend most of my work day faking positive emotions." Each item was rated on a 5-point scale (1=Strongly Disagree, 5=Strongly Agree). A composite emotional labor score was computed for each respondent by computing the average of the ratings given for all 13 items: the five emotional dissonance items and the eight items used to measure variety, frequency, and intensity.

Emotional exhaustion was measured using six items developed by Barnett, Brennan, and Gareis (1999). These authors reported a Cronbach's alpha of .89 for this six item measure. Using a 7 -point scale (1=never, 2=less than 12 times a year, 3= once a month, 4=more than once a month but less than once a week, 5=once a week, 6=2 to 4 times a week, 7= 5 times a week or more), respondents were instructed to indicate the frequency with which they felt a particular emotion. Sample items include: "emotionally drained," and "tired facing another day."

\section{$\underline{\text { Work-related beliefs and attitudes }}$}

The work-related beliefs and attitudes section consisted of three measures: (1) attitudes toward fun at work, (2) level of fun experienced at work, and (3) job satisfaction. All items in this section were rated on a 5-point scale (1=Strongly Disagree, 5=Strongly Agree). The measure of attitudes toward fun was developed using the three attitudinal categories of appropriateness, salience, and perceived consequences of fun. Four items measure appropriateness, five items measure salience, and 8 items measure perceived consequences. Three of the items were taken from the sample items provided by Aldag and Sherony (2001), the remaining items were developed by Karl and Harland (2005). The composite score was computed as the average of all 17 
items. The level of fun experienced at work was measured using 5 items developed by the authors. Job satisfaction was measured using 5 items from the Brayfield and Rothe's (1951) job satisfaction index, and when used in a previous study, a coefficient alpha of .88 was reported for this reduced 5 -item measure. Sample items include: "I feel fairly satisfied with my present job," and "Each day at work seems like it will never end."

\section{Results}

Table 1 contains the mean scores, standard deviations, correlations, and reliability coefficients for the variables measuring work-related emotions, attitudes toward fun, experienced fun, and job satisfaction. The mean scores indicate that respondents were generally satisfied with their jobs $(\mathrm{M}=3.7, \mathrm{SD}=.62$ on a 5 -point scale) and did not experience high levels of emotional labor ( $M=3.04, S D=.50$ on a 5-point scale), or emotional exhaustion ( $M=3.77$ on a 7-point scale). However, there was a considerable amount of variation in emotional exhaustion $(S D=1.2)$. Respondents expressed very positive attitudes towards fun $(\mathrm{M}=3.96, \mathrm{SD}=.38)$ and experienced a moderate level of fun in their workplaces $(M=3.16, S D=.63)$.

Table 1.

Means, Standard Deviations, Reliability Estimates, and Correlations for Variables Measuring Work-related Emotions and Attitudes

\begin{tabular}{llllllll}
\hline Variable & $\mathbf{M}$ & SD & $\mathbf{1}$ & $\mathbf{2}$ & $\mathbf{3}$ & $\mathbf{4}$ & $\mathbf{5}$ \\
\hline 1. Emotional Labor & 3.04 & .50 & $(.79)$ & & & & \\
2. Experienced Fun & 3.16 & .63 & $-.30^{\star *}$ & $(.79)$ & & & \\
3. Attitudes Toward Fun & 3.96 & .38 & -.14 & $.25^{\star *}$ & $(.84)$ & & \\
4. Emotional Exhaustion & 3.77 & 1.2 & $.42^{* \star *}$ & $-.33^{* * *}$ & $-.18^{*}$ & $(.87)$ & \\
5. Job Satisfaction & 3.7 & .62 & $-.31^{* \star *}$ & $.57^{\star * *}$ & $.20^{*}$ & $-.46^{* \star *}$ & $(.86)$ \\
\hline
\end{tabular}

Note: Coefficient alphas are in the diagonal, ${ }^{*} p<.05,{ }^{* *} p<.01,{ }^{* * *} p<.001$

As predicted in Hypothesis 1, we found a positive relationship between emotional labor and emotional exhaustion $(r=.42, p<.001)$. To test the second hypothesis, we conducted a regression analysis in which emotional exhaustion was entered first, followed by emotional labor. As predicted, emotional labor did not explain any additional variance in job satisfaction $\left(\Delta R^{2}=.00\right.$, n.s.) over that explained by emotional exhaustion (Beta $=-.46, R^{2}=.21, p<.001$ ), supporting Hypothesis 2 (see Table 2). Consistent with past research, those who experienced greater emotional exhaustion reported lower job satisfaction.

Table 2.

Regression Results for the Impact of Emotional Labor and Emotional Exhaustion on Job Satisfaction 


\begin{tabular}{lccccc}
\hline $\begin{array}{l}\text { Dependent Variable: Job } \\
\text { Satisfaction }\end{array}$ & Beta & s.e. & $\mathbf{t}$ & $\mathbf{R}^{\mathbf{2}}$ & $\mathbf{d f}$ \\
\hline $\begin{array}{l}\text { Model 1 } \\
\text { Emotional Exhaustion }\end{array}$ & -.46 & .05 & $-5.44^{* * *}$ & & \\
& & & & .21 & $1 / 113$ \\
& & & & & \\
Model 2 & & & & & \\
Emotional Exhaustion & -.46 & .05 & $-5.33^{* * *}$ & & \\
Emotional Labor & .02 & .02 & $.237^{\text {n.s. }}$ & & \\
& & & & .21 & $2 / 112$ \\
\hline
\end{tabular}

Note: The Betas presented are the standardized coefficients.

${ }^{*} p<.05,{ }^{* *} p<.01,{ }^{* * *} p<.001$

The third hypothesis predicted an interaction effect for emotional exhaustion and experienced fun on job satisfaction. Using a hierarchical moderated regression analysis, a significant interaction effect was found (see Table 3). More specifically, the negative impact of emotional exhaustion on job satisfaction was significantly lower for those who experienced higher levels of fun at work (see Figure 2), thereby providing support for hypothesis 3 . Finally, as predicted in hypothesis 4 , those respondents with a more positive attitude towards fun reported that they experienced more fun in the workplace $(r=.25, p<.01)$.

\section{DISCUSSION}

One of the most significant contributions of this study is our finding that experiencing fun in the workplace can lessen the negative impact of emotional exhaustion on job satisfaction. While there may be little that health care institutions can do to reduce the emotional demands of health care providers' work, it appears that efforts to improve the workplace environment may have positive implications for employees' mental health and job satisfaction. By providing opportunities for employees to experience fun in the workplace, health care organizations are also likely to benefit from lower staffing costs since both emotional exhaustion and job satisfaction are strongly related to turnover (Cordes \& Dougherty, 1993; Happell, Martin \& Pinikahana, 2003; Lee \& Ashforth, 1996). Such endeavors can also reap benefits in terms of one's reputation as an employer. A study by Hewitt Associates showed that those companies on Fortune's "100 Best Companies to Work For" have lower turnover rates and receive more employment applications than those not selected ("Benefits Payoff," 1999).

Table 3.

Hierarchical Moderated Regression Results for the Interaction Between Emotional Exhaustion and Experienced Fun on Job Satisfaction

\begin{tabular}{llllll}
\hline $\begin{array}{l}\text { Dependent Variable: Job } \\
\text { Satisfaction }\end{array}$ & Beta & $R^{2}$ & $\begin{array}{c}\text { Adj. } \\
R^{2}\end{array}$ & $\Delta R^{2}$ & $F$ Change (df) \\
\hline
\end{tabular}

Step 1 
Emotional Exhaustion

Experienced Fun

Step 2

$\begin{array}{lllllll}\text { Emotional Exhaustion x Experienced Fun } & .79 & .43 & .42 & .02 & 5.90 & (1,139)^{*}\end{array}$

Note: The Betas presented are those derived at the second step.

${ }^{*} p<.05,{ }^{* *} p<.01,{ }^{* * *} p<.001$

Figure 2.

The Interaction Between Emotional Exhaustion and Experienced Fun on Job Satisfaction.

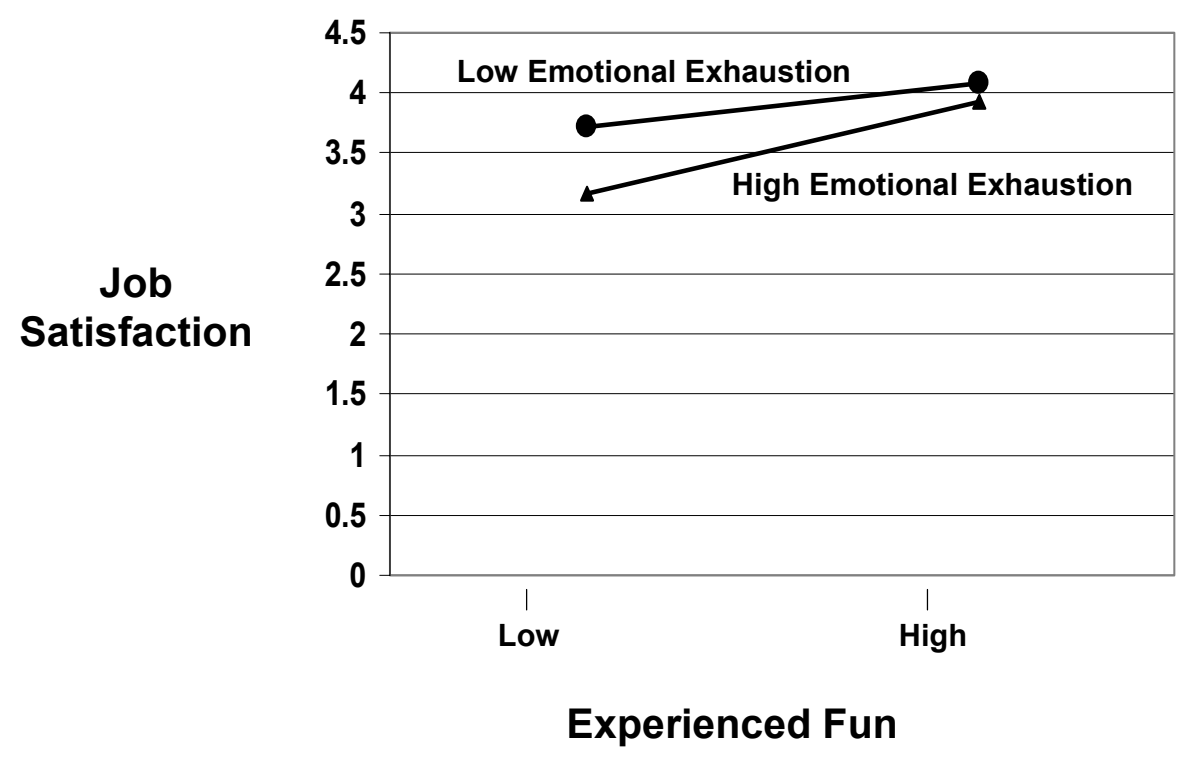

Another important finding of this study was that health care workers expressed positive attitudes toward workplace fun. Employees with positive attitudes towards fun were more likely to experience fun in the workplace, have higher job satisfaction, and suffer less emotional exhaustion. Health care institutions that might be considering the use of fun workplace activities can take comfort in the fact that these appear to be well received by employees and that the use of such activities are likely to result in positive outcomes for both the employees and the organization.

While our study produced some significant findings with regard to the benefits of a fun work environment, it also raises some interesting questions for future research. One important question that needs to be addressed is---what do health care workers consider to be fun? To date, there has been very limited research in this area. Two exceptions are a study of human resource professionals by Ford, McLaughlin, and Newstrom (2003) and a study of MBA students by Karl and Harland (2005). Ford et al. (2003) surveyed 572 human resource professionals and found that the top three most 
frequently used activities to create a fun work environment were casual dress days, employee recognition and rewards, and company-provided food and refreshments (these activities were used by $84 \%, 83 \%$, and $82 \%$, respectively). Some less frequently used activities included costume days (used by $39 \%$ of respondents), fun committees $(21 \%)$, and creative skits and songs for company events (20\%). In a study of $180 \mathrm{MBA}$ students, Karl and Harland (2005) identified 40 fun activities from recommendations made by authors in the popular press literature (e.g., Berger, 2002; Firth, 1995; Greenwich, 2000; Hemsath, 2001; Putzier 2001). These 40 activities were grouped into one of nine categories: (1) contests (e.g., baby picture, bake-off), (2) gift exchanges, (3) games (e.g., Bingo, cards, board games), (4) awards, (5) food and refreshments, (6) company-wide outings (e.g., golf, amusement park), (7) humorous communications, humor kits, or humor committees, (8) self-deprecation or "let's laugh at ourselves" activities (e.g., ugliest tie, employees share stories of most embarrassing moment), and (9) wild and wacky (e.g., office Olympics with office-related events such as wastebasket shot put, or theme days such as Hawaiian Day, or Halloween). These authors found that the types of fun activities most favored by respondents were company-wide outings (e.g., golf, baseball game, amusement park) and food-related events (e.g., everyone goes out to lunch once a month, potluck lunch or dinner, celebrate employees' birthdays with cake and ice cream).

However, it is possible that health care workers may differ in the types of fun activities they would prefer. Without such information, there is a risk that the use of some activities may have unintended consequences. Certain workplace activities, which are intended to be fun, may actually cause more stress or more emotional exhaustion. For instance, having a costume contest, theme day (Hawaiian, back tie, etc.) or potluck lunch may cause more stress for those who feel they have to spend their valuable offwork hours devoting time and money to either acquiring the appropriate attire or preparing food. Similarly, company-wide outings or celebrations scheduled during offwork hours may result in increased work-family conflict for those employees who would rather spend time with their families, but feel obligated to attend work-related events. A thorough investigation of various fun activities would aid health care organizations in their decisions about what kinds of activities would be most well received by employees.

Although this study did not examine patient satisfaction, there is evidence to suggest that the benefits of workplace fun for employees could have positive implications for patient satisfaction. However, this warrants further investigation given that there has been some debate as to whether more satisfied employees "create" more satisfied patients, or whether working with satisfied patients tends to make employees more satisfied (Kaldenberg \& Regrut, 1999). Furthermore, it would be important to examine patient reactions to workplace fun. Currently, there is no research which directly examines how customers/clients might react to seeing employees having fun at work. It is possible that while workplace fun may have positive effects for employees, those being served may feel that employees are goofing off and not devoting sufficient attention to them. This might be especially true in health care environments. Differences in patient reactions may also depend on where fun activities are being used in the health care workplace (e.g. clinic vs. hospital floor), given differences in the intensity of patient care needs. Thus, health care organizations should not consider this 
as a panacea for reducing employee emotional exhaustion, but as one possible tactic to be used in combination with other workplace environment changes.

This study is not without limitations. First, replication is needed. In general, our respondents reported low levels of emotional labor and low levels of emotional exhaustion. Thus, the relationships reported here may not be representative of those found in work environments eliciting higher levels of emotional labor and exhaustion. Another limitation is that there are undoubtedly several unmeasured variables that may play a significant role in the relationship between experienced fun, emotional exhaustion, and job satisfaction. For example, individual and situational variables such as personality (e.g., extroversion, agreeableness) or work context (e.g., emergency room, critical care) may influence both the perceived appropriateness and outcomes of workplace fun. Future research is needed to examine these possibilities.

In conclusion, there is ample anecdotal evidence suggesting that workplace fun can lead to positive outcomes. The results of this study provide empirical support for those claims. Future research addressing the issues raised above will help clarify the impact that fun in the workplace can have in the health care industry.

\section{References}

Aiken, L., Clarke, S., Sloane, D., Sochalski, J., \& Silber, J. (2002). Hospital Nurse Staffing and Patient Mortality, Nurse Burnout, and Job Dissatisfaction. JAMA: The Journal of the American Medical Association, 288(16), 1987-1994.

Aldag, R., \& Sherony, K. (2001). A Spoonful of Sugar: Some Thoughts on "Fun At Work". Current Issues in Management, 1(1), 62-76.

Ashforth, B., \& Humphrey, R. (1993). Emotional Labor in Service Roles: The Influence of Identity. Academy of Management Review, 18, 88-115.

Barnett, R. C., Brennan, R. T., Gareis, K. C. (1999). A Closer Look at The Measurement of Burnout. Journal of Applied Biobehavioral Research, 4(2), 65-78.

Benefits Payoff for the Best Companies. Compensation \& Benefits Report, 2/7/99, 13 (3), 4.

Berg, D. H. (2001). The Power of a Playful Spirit At Work. The Journal for Quality \& Participation, 24 (2), 57-62.

Berger, C. (2002). Funny Works!: 52 Ways to Have More Fun at Work. Encino, CA: SJS Press.

Best, R. G., Downey, R. G. \& Jones, R. G. (1997, April). Incumbent Perceptions of Emotional Work Requirements. Paper presented at the $12^{\text {th }}$ annual conference of the Society for Industrial and Organizational Psychology, St. Louis, MO. 
Brayfield, A. H. \& Rothe, H. F. (1951). An Index of Job Satisfaction. Journal of Applied Psychology, 35, 307-311.

Brotheridge, C.M., \& Lee, R. T. (2003). Development and Validation of the Emotional Labour Scale. Journal of Occupational \& Organizational Psychology, 76 (3), 365-379.

Broussine, M., Davies, F. \& Scott, J. C. (1999). Humour at the Edge: An Inquiry Into the use of Humour in British Social Work. Bristol Business School Teaching and Research Review, 1. Retrieved June 6, 2005 from: http://www.uwe.ac.uk/bbs/trr/lssue1//S12_1.htm, ISSN 1468-4578.

Cameron, S. J., Horsburgh, M. E. \& Armstrong, M. (1994). Job Satisfaction, Propensity to Leave and Burnout in Rns and Rnas: A Multivariate Perspective. Canadian Journal of Nursing Administration, 7 (3), 43-64.

Chan, K., Gee, M., \& Steiner, T. (2000). Employee Happiness and Corporate Financial Performance. Financial Practice \& Education, 10(2), 47-53.

Cordes, C., \& Dougherty, T. (1993). A Review and Integration of Research on Job Burnout. Academy of Management Review, 18, 621-656.

Dorz, S., Novara, C., Sica, C., \& Sanavio, E. (2003). Predicting Burnout Among HIVIAIDS and Oncology Health Care Workers. Psychology \& Health, 18(5), 677-685.

Employees "KACH-the-Attitude" with the FISH! Philosophy (n.d.). KACH Happenings. Retrieved March 11, 2004 from Knoxville Area Community Hospital web site: http://www.kach.org/happenings.htm.

Firth, D. (1995). How to Make Work Fun: An Alphabet of Possibilities. Hampshire, England: Gower Publishing.

FISH! Philosophy "Catches On" at Silver Cross Hospital (2003, December). News Releases. Retrieved March 29, 2004 from Silver Cross Hospital web site: http://www.silvercross.org/whats new/2003-12-04 fish.shtml.

Ford, R. C., McLaughlin, F. S. \& Newstrom, J. W. (2003). Questions and Answers About Fun at Work. Human Resource Planning, 26 (4), 18-33.

Gibson, L. (2004). Tickling your funny bone. Nursing, 34(1), 70-71.

Gorman, H. (2000). Winning Hearts and Minds? Emotional Labour and Learning For Care Management Work. Journal of Social Work Practice, 14(2), 149-159.

Greenwich, C. (2001). Fun and Gains: Motivate and Energize Staff with Workplace Games, Contests and Activities. Sydney, Australia: McGraw-Hill Australia.

Happell, B., Martin, T., \& Pinikahana, J. (2003). Burnout and Job Satisfaction: A Comparative Study of Psychiatric Nurses from Forensic and a Mainstream Mental Health Service. International Journal of Mental Health Nursing, 12(1), 39-47. 
Hemsath, D. (2001). 301 More Ways to Have Fun at Work. San Francisco: BerrettKoehler Publishers, Inc.

Henderson, A. (2001). Emotional Labour and Nursing: An Under-Appreciated Aspect of Caring Work. Nursing Inquiry, 8(2), 130-139.

Hochschild, A. (1983). The Managed Heart: Commercialization Of Human Feeling. Berkeley: University of California Press.

Jackson, S. E., Schwab, R. L., \& Schuler, R. S. (1986). Toward an Understanding of the Burnout Phenomenon. Journal of Applied Psychology. 71(4), 630-640.

James, N. (1989). Emotional Labour Skill and Work in The Social Regulation of Feelings. Sociological Review, 37, 15-42.

Joyce, K. (2003). Lessons for Employers from Fortune's 100 Best. Business Horizons, 46(2), 77.

Kahn, W. A. (1983). Caring for the Caregivers: Patterns of Organizational Caregiving. Administrative Science Quarterly, 38, 539-563.

Kaldenberg D.O., \& Regrut, B.A. (1999). Do Satisfied Patients Depend on Satisfied Employees? Or Do Satisfied Employees Depend on Satisfied Patients? Health Care Registration: The Newsletter for Health Care Registration Professionals, 9 (1), 10-12.

Karl, K.A., \& Harland, L. 2005. What's Fun and What's Not: An Examination of Age, Gender Differences, and Attitudes Toward Fun Activities at Work. Proceedings of the Midwest Academy of Management. Retrieved June 6, 2005 at: http://www.midwestacademy.org/Proceedings/2005/index.html.

Kruml, S. M. \& Geddes, D. (2000). Exploring the Dimensions of Emotional Labor. Management Communication Quarterly, 14 (1), 8-49.

Larson, E. B. \& Yao, X. (2005). Clinical Empathy as Emotional Labor in the PatientPhysician Relationship. JAMA : The Journal of the American Medical Association, 293(9), 1100-1106.

Lee, R. T. \& Ashforth, B. E. (1996). A Meta-Analytic Examination of the Correlates of the Three Dimensions of Job Burnout. Journal of Applied Psychology. 81 (2), 123-133.

Lundin, S., Paul, H., \& Christensen, J. (2002). Fish! A Remarkable Way to Boost Morale and Improve Results. New York, NY: Hyperion.

Lundin, S., Christensen, J., Paul, H., \& Strand, P. (2002). Fish! Tales: Real-Life Stories to Help Transform Your Workplace and Your Life. New York, NY: Hyperion.

Mariotti, J. (1999). A Company That Plays Together, Stays Together. Industry Week, $248(6), 63$. 
Martin, R. A. (1996). Humour as Threrapeutic Play: Stress-Moderating Effects of Sense of Humour. Journal of Leisurability, 23 (4). Retrieved June 6, 2005 at:: http://www.lin.ca/resource/html/Vol23/v23n4a3.htm.

Maslach, C. (1982). Burnout: The Cost of Caring. Englewood Cliffs, NJ: Prentice-Hall.

McGhee, P. (2000). The Key to Stress Management, Retention, and Profitability? More Workplace Fun. HR Focus, 77(9), 5-6.

Mellen, K. (2003, February). Fish! tackles workplace morale. Workers all over the country have 'gone fishing'. GazetteNet. Retrieved March 29, 2004 at http://www.gazettenet.com/business/02242003/3715.htm.

Meyer, H. (1999). Fun for Everyone. Journal of Business Strategy, 20 (2), 13-17.

Moore, J. E. (2000). Why is this happening? A Causal Attribution Approach to Work Exhaustion Consequences. Academy of Management Review, 25(2), 335-49.

Morris, J. A., \& Feldman, D. C. (1997). Managing Emotions in the Workplace. Journal of Managerial Issues, 9(3), 257-274.

Patient Care Performed With Flair (n.d.). Retrieved March 29, 2004 from Banner Health web site:

http://www.bannerhealth.com/channels/patients+and+visitors/facilities/arizona/ thunderbird/_patient+care+story.asp

Paulson, A. (2001). Fun at the Firm: The Role of Play at Work. Christian Science Monitor, 94(17), 16.

Putzier, J. (2001). "Get Weird!": 101 Innovative Ways to Make Your Company a Great Place to Work. New York: AMACOM.

Ramsey, R. (2001). Fun at Work: Lessons From the Fish Market. Supervision, 62(4), 79.

Scott, A. (2000). Emotion, Moral Perception, and Nursing Practice. Nursing Philosophy, 1(2), 123-134.

Waldrop, S. (2003). Battling Burnout: Maintaining Enthusiasm in a Challenging Environment. Physical Therapy, 11(6), 38-46.

Weiss, J. (2002). Loyal Employees or The Revolving Door? Executive Excellence, 19(6), 17.

Wharton, A. S. (1993). The Affective Consequences of Service Work. Work and Occupations, 20, 205-232.

Wooten, P. (1993). Making Humor Work: Results of the JNJ Humor Study. Journal of Nursing Jocularity, 3(4), 46-47. 
